\title{
Perspectives on gender parity in bioanalysis: an interview with Atreyee Sims
}

\author{
Atreyee Sims*,1 \\ ${ }^{1}$ PRA Health Sciences, 11070 Strang Line Road, Lenexa, KS 66215, USA \\ *Author for correspondence: SimsAtreyee@prahs.com
}

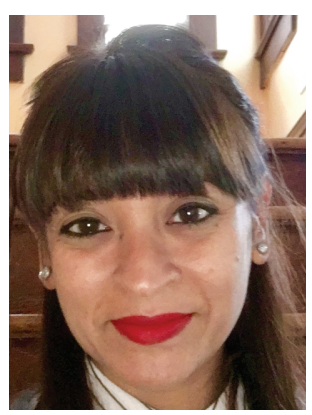

\section{Biography:}

Atreyee Sims is an accomplished and committed GCP/GLP trained Project Manager overseeing Phase I-III clinical trials with a strong scientific acumen in pharmacology, microbiology and molecular biology. Project delivery emboldened by 10 years' experience as a Clinical Laboratory Scientist and Microbiologist with more than ten published peer-reviewed manuscripts. Spearheads project leadership role in GCP/GLP and protocol-compliant tracking of project results, implements data collection procedures and verifies project data to ensure timely delivery with the highest priority of both subject safety and data integrity. Proactively identifies, resolves/mitigates and escalates risks and/or issues and responsible for building key partnerships. Excels in team leadership with impeccable organization skills, superior technical writing, communication and problem-solving skills.

Accepted for publication: 5 March 2019; Published online: 18 April 2019

What advice would you give to young women hoping to embark on a career in the field?

- Know what brings you joy, do not always think about the salary;

- Job-shadowing can benefit during your career exploration. Take advantage of it if you have a relative or friend who does what you have always dreamed of doing;

- Be bold and do not hesitate to show off your skill sets.

\section{What are the most valuable skill sets women/diversity bring to an organization?}

- Improves employee performance. When a company includes women and people from different diverse cultural and social backgrounds, employees start to feel a sense of being wanted from their employers;

- It grows your talent pool because the flow of ideas that comes in from these women is limitless;

- Creativity and multitasking skills can multiply the growth of an organization.

\section{What do you see as being the most effective solution to getting more women involved in}

\section{STEM careers?}

- Start at an early age, like from the age of two, where instead of buying princess dolls for your girl and a truck set for your boy, buy them both puzzles, Legos, truck sets. We as parents need to stop differentiating our kids based off gender-appropriate toys. As a woman (be it a sister, aunt, mother, grandmother) encourage your girls to go on an expedition every time you are changing a tire, or fixing a light bulb or checking your breaker box. Introducing your high schooler to a bootcamp for robotics or math club is not enough. Start early. That is, to my knowledge, the most effective solution to getting more and more girls (mind you, I do not say women) involved in Science, Technology, Engineering, Maths (STEM) careers.

\section{How did you overcome obstacles in your scientific career? Can you share any useful} information others can use in their own careers?

- Obstacles can be found at work, at home, in everyday life. It does impede your progress. But I refused to be discouraged by these defeats and saw an opportunity;

- At work I overcame my obstacles by being powerful and assertive and decided to boldly walk through them; 
- Meekness will not take you anywhere in life. We as women are all very strong. We just need to find the voice within us to portray our strength and let it out.

How do you mange work/life balance in your busy schedule \& what advice would you like to give to young women who are starting their careers?

- I am all for compartmentalizing my life. As a mom of two girls under 4 years old, I have had to find a happy medium when it comes to bringing work home. Some days you just cannot avoid working in front of your kids, but I try to make sure I am sitting with my family during meal times and turning off my laptop;

- Focus your time and attention on things you can control.

\section{How would you like to inspire the next generation of girls/women in STEM?}

1. I would encourage young women to be confident and fearless. It is indeed a daunting task to choose a field at an early age that will eventually lead you to a lifelong career but you have to look past your fears of entering a male-dominated field with hopes of making your own mark. Coming from India and from a family that had no idea of STEM besides the traditional medical and engineering fields, I had to take it upon myself to explore classes like biochemistry, environmental microbiology, pharmacology, genetics, etc. in college. I worked as an $\mathrm{R} \& \mathrm{D}$ scientist in the pharmaceutical industry for 5 years and transitioned into being a PI (Principal Investigator/Project Manager [PM]) 2 years ago. Pursuing what made me happy has been way more rewarding than trying to fit into the traditional vocation of a doctor or an engineer. More women role models are needed in these STEM fields and I hope to inspire more by being authentic, curious and fearless.

\section{Disclaimer}

The opinions expressed in this interview are those of the interviewee and do not necessarily reflect the views of Future Science Group.

Financial \& competing interests disclosure

The author has no relevant affiliations or financial involvement with any organization or entity with a financial interest in or financial conflict with the subject matter or materials discussed in the manuscript. This includes employment, consultancies, honoraria, stock ownership or options, expert testimony, grants or patents received or pending, or royalties.

No writing assistance was utilized in the production of this manuscript. 